\title{
Wildlife cancer and plastic pollution
}

\section{Denise McAloose and Alisa L. Newton}

We would like to thank Thomas Erren, Dominique Zeuß, Frank Steffany, and Benno Meyer-Rochow for their thought-provoking comments on our Science and Society article (Wildlife cancer: a conservation perspective. Nature Rev. Cancer 9, 517-526 (2009)) ${ }^{1}$. The information provided by Erren, Zueß, Steffany and Meyer-Rochow (Increase of wildlife cancer: an echo of plastic pollution? Nature Rev. Cancer 09 Oct 2009 (doi:10.1038/ nrc2665-c1) $)^{2}$ complements the article's discussion regarding the importance of wild animals as sensitive indicators of anthropogenic factors and the recognition that these factors affect the health of all species and environments around the globe. As Erren and colleagues describe, there are many unanswered questions regarding the short- and long-term effects of environmental toxins, including plastics. Recent reviews examining the environmental threat posed by plastics ${ }^{3}$, and specifically bisphenol A (BPA $)^{4}$, support the role of wildlife health monitoring and research in bridging the gap between an in vitro understanding of the mechanisms of action and effects of toxins and the actual health risks of exposure in complicated natural settings. There is, and will continue to be, a tremendous need for immediate conservation interventions that address the global problem of pollution, as well as expanded, focused research in animals and humans. This research is needed to better understand the direct and indirect effects of toxins not only in cancer but also in other diseases.

Denise McAloose and Alisa L. Newton are at Pathology and Disease Investigation, Global Health Program, Wildlife Conservation Society, 2300 Southern Boulevard, Bronx, New York, New York 10460, USA. Correspondence to D.M. e-mail:ㄹmcaloose@wcs.org doi:1038/nrc2665-c2

1. McAloose, D. \& Newton, A. L. Wildlife cancer: a conservation perspective. Nature Rev. Cancer 9 517-526 (2009).

2. Erren, T., Zueß, D., Steffany, F. \& Meyer-Rochow, B. Increase of wildlife cancer: an echo of plastic pollution? Nature Rev. Cancer 09 Oct 2009 (doi: 10.1038/nrc2665-c1).

3. Thompson, R. C., Moore, C. J., vom Saal, F. S. \& Swan, S. H. Plastics, the environment and human health: current consensus and future trends. Philos. Trans. R. Soc. Lond. B Biol. Sci. 364, 2153-2166 (2009).

4. Crain, D. A. et al. An ecological assessment of bisphenol-A: evidence from comparative biology. Reprod. Toxicol. 24, 225-239 (2007). 